\title{
HUBUNGAN PENGETAHUAN DAN SIKAP IBU DENGAN PERILAKU PENCEGAHAN STUNTING PADA BALITA
}

\author{
Zahrotul Mutingah1), Rokhaidah²) \\ 1,2Fakultas Ilmu Kesehatan \\ 1,2Universitas Pembangunan Nasional Veteran Jakarta
}

\begin{abstract}
ABSTRAK
Stunting merupakan masalah kekurangan gizi yang masih dialami balita di seluruh dunia, termasuk Indonesia. Dalam menurunkan prevalensi stunting diperlukan perilaku pencegahan, yang dapat dipengaruhi oleh pengetahuan dan sikap seseorang. Penelitian ini dilakukan untuk mengetahui hubungan antara pengetahuan dan sikap ibu dengan perilaku pencegahan stunting pada balita di Posyandu Tunas Mekar 1 Kelurahan Krukut, Depok. Penelitian ini menggunakan metode kuantitatif dengan desain Cross Sectional. Sampel dipilih menggunakaan teknik total sampling melibatkan 74 ibu balita. Pengumpulan data menggunakan kuesioner yang sudah teruji validitas serta reliabilitasnya dan dibagikan langsung kepada responden. Hasil penelitian menunjukkan bahwa secara statistik tidak terdapat hubungan antara pengetahuan dengan perilaku pencegahan stunting ( $\mathrm{p}$ value $=0,100)$, namun terdapat hubungan antara sikap ( $\mathrm{p}$ value $=0,001$ ) dan status pekerjaan ibu ( $\mathrm{p}$ value $=0,003)$ dengan perilaku pencegahan stunting $(<0,05)$. Peneliti selanjutnya direkomendasikan untuk mengambil sampel lebih banyak serta menganalisis faktor lain yang dapat mempengaruhi perilaku seperti pendapatan, budaya, dan dukungan.
\end{abstract}

Kata kunci : Pengetahuan, Sikap, Perilaku Pencegahan Stunting

\begin{abstract}
Stunting is a nutritional deficiency problem that is still experienced by toddlers throughout the world, including Indonesia. In reducing the prevalence of stunting, preventive behavior is needed, which can be influenced by a person's knowledge and attitude. This study was conducted to determine the relationship between knowledge and attitudes of mothers with stunting prevention behavior in toddlers at Posyandu Tunas Mekar 1 Krukut Village, Depok. This study used a quantitative method with a cross sectional design. The sample was selected using a total sampling technique with 74 mothers of children under five. Collecting data using a questionnaire that has been tested for validity and reliability and distributed directly to respondents. The results showed that statistically there was no relationship between knowledge with stunting prevention behavior ( $p$ value $=0.100$ ), but there was a relationship between attitude $(p$ value $=0.001)$ and maternal employment status $(p$ value $=$ $0.003)$ with stunting prevention behavior $(<0.05)$. Further researchers are recommended to take more samples and analyze other factors that can influence behavior such as income, culture, and support.
\end{abstract}

Keywords: Knowledge; Attitude; Stunting Prevention Behavior

Alamat korespondensi: Fakultas Ilmu Kesehatan, Universitas Pembangunan Nasional Veteran Jakarta, Jalan Limo Raya Kelurahan Limo Kecamatan Limo Kota Depok Kode Pos 16515

Email: zahrotulmutingah@upnvj.ac.id, rokhaidah@upnvj.ac.id 


\section{PENDAHULUAN}

Stunting mengacu pada anak yang terlalu pendek untuk usianya (UNICEF, WHO, \& World Bank, 2020). Stunting adalah kondisi ketika tubuh balita tidak mencapai panjang atau tinggi badan yang sesuai menurut usianya. Balita dikatakan stunting apabila hasil pengukuran PB atau TB menunjukkan <-2 SD (standar deviasi) dari median standar pertumbuhan berdasarkan WHO. Hal ini dapat diakibatkan karena kekurangan zat gizi kronis. Kejadian stunting pada balita dapat disebabkan oleh beberapa faktor diantaranya berasal dari situasi ibu yaitu kesehatan serta gizinya baik sebelum, saat masa kehamilan, maupun setelah melahirkan sehingga berdampak pada pertumbuhan anak atau janin. Sedangkan dari situasi bayi dan balita penyebab stunting diantaranya adalah tidak dilakukannya inisiasi menyusui dini (IMD), tidak mendapat ASI eksklusif serta Makanan Pendamping ASI (MP-ASI) (Pusdatin Kemenkes RI, 2018). Selain itu, stunting juga dapat disebabkan oleh faktor terbatasnya akses pelayanan kesehatan ibu selama dan setelah kehamilan, belum optimalnya akses keluarga ke makanan yang bergizi, serta belum cukupnya akses ke air yang bersih juga sanitasi (TNP2K, 2017).

Prevalensi balita yang mengalami stunting di dunia pada tahun 2019 menunjukkan ada sekitar 21,3\% atau 144 juta anak balita yang masih mengalami stunting (UNICEF et al., 2020). Indonesia sendiri, memiliki prevalensi anak dibawah lima tahun yang mengalami stunting sebanyak 27,7\% (SSGBI, 2019). Meskipun prevalensi stunting telah menurun dari tahun sebelumnya, target prevalensi stunting yang ditentukan dalam Rencana Pembangunan Jangka Menengah Nasional (RPJMN) tahun 2020-2024 adalah 14\% (Peraturan Presiden RI, 2020). Pada tahun 2019, seperti prevalensi nasional, prevalensi stunting di Jawa Barat juga telah menurun menjadi sekitar 25,7\% (SSGBI, 2019). Sementara menurut data Dinas Kesehatan Depok, pada tahun 2019 jumlah balita usia 0-59 bulan yang pendek (stunting) sebanyak 5,241 atau sekitar 4,6\% (Dinas Kesehatan Kota Depok, 2020).

Stunting pada anak dapat mempengaruhi tingkat kecerdasan dan status kesehatannya saat dewasa (Kemenkes RI, 2018). Anak yang menderita stunting dapat menderita kerusakan fisik serta kognitif dan menyebabkan pertumbuhannya terhambat (UNICEF et al., 2020). Kondisi tersebut yang terus menerus berlangsung akan menurunkan kualitas serta produktifitas masa depan warga negara indonesia (Harikatang et al., 2020). Oleh sebab itu, dalam upaya mencegah hal tersebut dibutuhkan upaya penanggulangan masalah stunting. Penanggulangan stunting meliputi upaya pencegahan serta penanganan. Upaya pencegahan sendiri dapat dilakukan dengan memastikan bahwa anak memiliki status kesehatan yang baik, mendapat gizi cukup pada 1000 Hari Pertama Kehidupan (HPK), serta mendapat imunisasi dan pola hidup bersih untuk mencegah penyakit. Cara pencegahan yang dapat dilakukan orang tua untuk mencegah buah hati dari stunting meliputi; (1) Memenuhi kebutuhan gizi pada 1000 HPK anak, (2) Memenuhi kebutuhan nutrisi bagi ibu hamil, (3) Konsumsi protein dengan kadar yang sesuai bagi anak diatas 6 bulan, (4) Menjaga kebersihan sanitasi serta memenuhi kebutuhan air bersih, dan (5) Rutin membawa anak ke posyandu minimal sekali dalam sebulan (Kemenkes RI, 2018).

Kunci keberhasilan pencegahan stunting salah satunya adalah perilaku kesehatan masyarakat sendiri (Kemenkes RI, 2018). Menurut teori Health Promotion Model, perilaku seseorang dipengaruhi oleh karakteristik dan pengalamannya. Sementara itu, teori Lawrence Green menyebutkan tiga faktor yang memiliki pengaruh dengan perilaku dalam kesehatan yakni faktor predisposisi, pendukung serta faktor pendorong. Predisposisi perilaku adalah faktor pengetahuan, kepercayaan, sikap, nilai dan keyakinan (Asmuji \& Faridah, 2018). Pengetahuan diartikan sebagai suatu hasil dari proses pengindraan yang membuat seseorang tahu. Dapat dikatakan bahwa pengetahuan termasuk bagian penting yang mempengaruhi tindakan atau perilaku seseorang (Hasmi, 2016). Sedangkan, sikap berarti besarnya perasaan baik positif atau negatif terhadap suatu hal, objek, orang, institusi atau kegiatan. Apabila seseorang memiliki keyakinan dan merasa bahwa dengan melakukan suatu 
perilaku akan menghasilkan keluaran yang positif, maka sikap positif pun akan ia miliki, begitu juga sebaliknya (Asmuji \& Faridah, 2018).

Ariestia (2020), dalam penelitiannya menunjukan ada hubungan antara pengetahuan ibu juga sikapnya terhadap pencegahan stunting. Penelitian lain juga menunjukkan sikap ibu memiliki hubungan dengan upaya pencegahan stunting, namun tidak terdapat hubungan dari pengetahuan ibu dengan upaya pencegahan stunting. Penelitian ini membahas bahwa dalam pencegahan stunting, sikap ibu termasuk dalam pemberian makanan pada anak merupakan hal yang penting karena dengan sikap yang baik dan didukung oleh pengetahuan tinggi akan tercermin perilaku positif (Arnita, Rahmadhani, \& Sari, 2020). Sementara, penelitian yang menunjukkan tidak terdapat hubungan pengetahuan dan sikap ibu dengan stunting membahas bahwa pengetahuan baik belum tentu menghasilkan sikap juga perilaku yang baik (Harikatang et al., 2020).

Upaya yang telah dilaksanakan pemerintah dalam meningkatkan perilaku masyarakatnya dalam mencegah stunting disusun dalam strategi nasional yang terdiri dari 5 pilar percepatan pencegahan stunting, tepatnya pada pilar 2 yang berbunyi kampanye nasional serta komunikasi perubahan perilaku (Kemenkes RI, 2018). Strategi untuk mencapai pilar tersebut adalah dengan meningkatkan komunikasi antar pribadi melalui pengembangan pesan yang disesuaikan dengan kebutuhan kelompok sasaran yaitu Rumah Tangga 1.000 HPK, WUS, dan remaja putri. Berbagai saluran komunikasi seperti posyandu, kelas pengasuhan, kelas ibu hamil, hingga konseling reproduksi remaja telah digunakan dalam penyampaian pesan ini (TNP2K, 2019).

Studi pendahuluan yang telah dilakukan di Posyandu Tunas Mekar 1 Kelurahan Krukut, Depok menunjukkan hasil dari 10 ibu balita yang diwawancarai mengenai pengetahuan tentang stunting mayoritas menunjukkan pengetahuan ibu masih kurang. Ibu mengatakan hanya pernah mendengar namun tidak tau pengertian, penyebab, serta dampaknya, dan belum pernah mendapatkan penyuluhan mengenai gizi. Selain itu, 3 dari 10 ibu juga memiliki sikap yang kurang baik seperti tidak berusaha mencari tahu tentang apa saja masalah gizi anak karena menganggap anak sudah memiliki gizi yang baik. Selain itu, 5 dari $10 \mathrm{ibu}$ sudah memiliki perilaku yang baik dalam mencegah stunting pada anaknya seperti memberi kolostrum dan ASI eksklusif, memastikan anaknya mengkonsumsi makanan sehat, serta memastikan diri dan anak menjaga kebersihan dengan mencuci tangan, namun 5 ibu lainnya memiliki perilaku kurang baik seperti tidak memberi ASI 6 bulan pertama, dan sering memberi makanan yang anak minta tanpa melihat kandungan gizinya.

\section{METODE PENELITIAN}

Metode kuantitatif dengan desain cross sectional digunakan dalam penelitian ini. Populasi pada penelitian ini yaitu seluruh ibu yang memilliki balita dengan usia 6-59 bulan di Posyandu Tunas Mekar 1 Kelurahan Krukut, Depok yang berjumlah 74 ibu balita. Penelitian ini menggunakan teknik sampel total atau sampel jenuh, dimana seluruh populasi dijadikan sebagai sampel. Kriteria inklusi dalam penelitian ini adalah ibu yang memiliki balita dengan usia 6-59 bulan, tinggal di wilayah Posyandu Tunas Mekar 1 Kelurahan Krukut, depok, dapat membaca dan menulis, serta menyatakan bersedia untuk menjadi responden penelitian. Sedangkan kriteria eksklusinya adalah ibu yang tidak sedang berada ditempat saat penelitian berlangsung, ibu yang pindah dari wilayah penelitian, dan ibu dengan anak yang memiliki keterbatasan fisik. Penelitian dilaksanakan sejak bulan Februari 2021 sampai dengan bulan Juni 2021. Pengumpulan data dilakukan dengan memberikan kuesioner dalam bentuk kertas yang terdiri dari 4 bagian meliputi karakteristik ibu dan balita, kuesioner pengetahuan tentang stunting, sikap terhadap pencegahan stunting, serta perilaku dalam mencegah stunting. Kuesioner tersebut merupakan kuesioner yang dikembangkan oleh peneliti dan sudah diuji validitas dengan nilai $r$ hitung $>0,361$ untuk setiap butir pernyataan, serta uji reliabilitas dengan nilai cronbach alpha 0,826 untuk kuesioner pengetahuan, 0,917 untuk kuesioner sikap dan 0,669 untuk kuesioner perilaku pencegahan stunting. Analisis yang digunakan dalam penelitian ini adalah Analisa univariat dan bivariat. Pada analisa bivariat digunakan tiga jenis uji, diantaranya uji Korelasi 
Spearman, Mann Whitney dan Kruskal Wallis. Penelitian ini menganalisis hubungan dari variabel independen yaitu pengetahuan dan sikap ibu, serta variabel confounding yaitu usia, pendidikan, dan pekerjaan ibu dengan variabel dependen yaitu perilaku pencegahan stunting.

\section{HASIL DAN PEMBAHASAN}

Hasil analisa univariat dari karakteristik ibu (usia, pendidikan, pekerjaan), karakteristik anak (usia, jenis kelamin, status gizi), pengetahuan, sikap dan perilaku ibu dapat dilihat pada tabel 1 hingga 3. Sedangkan hasil analisa bivariat antara karakteristik ibu, pengetahuan dan sikap dengan perilaku pencegahan stunting dapat dilihat pada tabel 4 hingga 6 .

Tabel 1. Distribusi Rata-rata Karakteristik Ibu dan Karakteristik Balita Menurut Usia (n=74)

\begin{tabular}{lccccccc}
\hline \multirow{2}{*}{ Karakteristik } & \multirow{2}{*}{ Mean } & \multirow{2}{*}{ Median } & \multirow{2}{*}{ SD } & \multicolumn{2}{c}{ 95\% CI } & \multirow{2}{*}{ Min } & \multirow{2}{*}{ Max } \\
\cline { 5 - 6 } & & & & Lower & Upper & & \\
\hline Usia Ibu (Tahun) & 32,41 & 32,50 & 5,828 & 31,06 & 33,76 & 22 & 46 \\
\hline Usia Balita (Bulan) & 30,39 & 27,00 & 15,029 & 26,91 & 33,87 & 6 & 59 \\
\hline
\end{tabular}

Tabel 1 memperlihatkan hasil pada karakteristik ibu menurut usia, rata-rata usia ibu di Posyandu Tunas Mekar 1 Kelurahan Krukut adalah 32,41 tahun dengan usia termuda 22 tahun dan tertua 46 tahun. Sementara rata-rata balita berusia 30,39 bulan, dengan usia balita paling muda yaitu 6 bulan dan paling tua yaitu 59 bulan.

Tabel 2. Distribusi Frekuensi Karakteristik Ibu Menurut Pendidikan dan Pekerjaan, serta Karakteristik Balita Menurut Jenis Kelamin dan Status Gizi (n=74)

\begin{tabular}{llcc}
\hline \multicolumn{1}{c}{ Karakteristik } & \multicolumn{1}{c}{ Kategori } & Frekuensi & Persentase \\
\hline Pendidikan Ibu & Pendidikan Dasar & 17 & $23 \%$ \\
& Pendidikan Menengah & 45 & $60,8 \%$ \\
& Pendidikan Tinggi & 12 & $16,2 \%$ \\
\hline Pekerjaan Ibu & Bekerja & 19 & $25,7 \%$ \\
& Tidak Bekerja & 55 & $74,3 \%$ \\
\hline Jenis Kelamin Balita & Laki-laki & 33 & $44,6 \%$ \\
& Perempuan & 41 & $55,4 \%$ \\
\hline \multirow{2}{*}{ Status Gizi Balita (TB/U) } & Stunting & 13 & $17,6 \%$ \\
& Tidak Stunting & 61 & $82,4 \%$ \\
\hline
\end{tabular}

Tabel 2 memperlihatkan hasil bahwa dari 74 ibu balita, mayoritas ibu berada pada tingkat pendidikan menengah sebanyak 45 orang $(60,8 \%)$. Sedangkan berdasarkan status pekerjaan, $55 \mathrm{ibu}$ $(74,3 \%)$ tidak bekerja atau hanya sebagai ibu rumah tangga. Pada karakteristik balita, tabel diatas memperlihatkan bahwa berdasarkan jenis kelamin, dari 74 balita, mayoritas atau sebanyak 41 balita $(55,4 \%)$ berjenis kelamin perempuan. Sedangkan berdasarkan kategori status gizi balita menurut Tinggi Badan per Usia (TB/U), 61 balita $(82,4 \%)$ tidak mengalami stunting.

Tabel 3. Distribusi Rata-rata Variabel Pengetahuan dan Sikap Ibu tentang Stunting (n=74)

\begin{tabular}{lccccccc}
\hline \multirow{2}{*}{ Variabel } & \multirow{2}{*}{ Mean } & \multirow{2}{*}{ Median } & \multirow{2}{*}{ SD } & \multicolumn{2}{c}{ 95\% CI } & \multirow{2}{*}{ Min } & \multirow{2}{*}{ Max } \\
\cline { 5 - 6 } Pengetahuan Ibu & 11,64 & 13,00 & 3,023 & 10,93 & 12,34 & 4 & 16 \\
\hline Sikap Ibu & 57,45 & 57,00 & 5,420 & 56,19 & 58,70 & 47 & 64 \\
\hline Perilaku Ibu & 8,20 & 8,00 & 1,227 & 7,92 & 8,49 & 5 & 10 \\
\hline
\end{tabular}


Tabel 3 memperlihatkan hasil rata-rata skor pengetahuan ibu balita tentang stunting yaitu 11,64 atau sebanyak 72,75\% pernyataan pengetahuan dapat dijawab benar oleh responden, yang jika dikategorikan termasuk pengetahuan cukup baik. Pada variabel sikap ibu tentang pencegahan stunting, rata-rata skor sikap ibu menunjukkan hasil 57,45. Sementara, hasil rata-rata skor perilaku ibu balita dalam pencegahan stunting adalah 8,20. Jika dikategorikan dengan nilai median sebagai cut off point, rata-rata ibu memiliki sikap dan perilaku yang baik dalam mencegah stunting.

\section{Tabel 4. Analisa Hubungan Karakteristik Ibu yaitu Usia dengan Perilaku Ibu dalam Pencegahan Stunting $(\mathrm{n}=74)$}

\begin{tabular}{lccc}
\hline \multirow{2}{*}{ Analisa } & \multicolumn{3}{c}{ Perilaku Ibu dalam Pencegahan Stunting } \\
\cline { 2 - 4 } & r spearman & $\boldsymbol{P}$ value & $\mathbf{n}$ \\
\hline Usia Ibu & 0,121 & 0,305 & 74 \\
\hline
\end{tabular}

Tabel 5. Analisa Hubungan Karakteristik Ibu yaitu Pendidikan dan Pekerjaan dengan Perilaku Ibu dalam Pencegahan Stunting $(n=74)$

\begin{tabular}{lccc}
\hline \multirow{2}{*}{ Karakteristik Ibu } & \multicolumn{3}{c}{ Perilaku Ibu dalam Pencegahan Stunting } \\
\cline { 2 - 4 } & n & P value & Mean Rank \\
\hline Pendidikan Ibu & & & \\
\hline a. Pendidikan Dasar & 17 & 0,053 & 45,50 \\
b. Pendidikan Menengah & 45 & & 37,42 \\
c. Pendidikan Tinggi & 12 & & \\
\hline Pekerjaan Ibu & & \multirow{2}{*}{0,003} & 25,39 \\
\hline a. Bekerja & 19 & & 41,68 \\
b. Tidak Bekerja & 55 & & \\
\hline
\end{tabular}

Tabel 4 menunjukkan bahwa antara variabel usia ibu dengan perilaku ibu dalam pencegahan stunting memiliki $\mathrm{p}$ value $=0,305(>0,05)$ sehingga dapat dinyatakan bahwa secara statistik tidak terdapat hubungan antara usia ibu dengan perilaku ibu dalam mencegah stunting. Hasil penelitian yang ditunjukkan ini dengan hasil penelitian Salamung et al. (2019) tidak jauh berbeda, yaitu bahwa berdasarkan perhitungan statistik tidak ada hubungan yang bermakna antara rentang usia responden dengan perilaku mencegah stunting dengan $\mathrm{p}$ value $=0,317(>0,05)$. Tidak adanya hubungan bermakna antara kedua variabel tersebut dapat disebabkan oleh faktor lain seperti motivasi ibu. Motivasi termasuk faktor utama dalam diri seseorang untuk melakukan suatu yang ingin dicapai. Motivasi ibu untuk menerapkan perilaku kesehatan juga akan sangat dipengaruhi oleh dukungan dari orang terdekat ibu (Wulandari \& Kusumastuti, 2020). Berdasarkan hasil uji statistik serta teori yang ada, peneliti memiliki asumsi bahwa usia ibu tidak dapat menjadi patokan baik atau buruknya perilaku, karena banyak faktor lain yang mempengaruhi. Ibu yang memiliki usia lebih muda bisa saja memiliki motivasi ataupun dukungan yang lebih baik untuk melakukan perilaku pencegahan stunting dari orang disekitarnya, ataupun sebaliknya.

Tabel 5 memperlihatkan hasil analisa uji Kruskal Wallis antara variabel pendidikan ibu dengan perilakunya dalam mencegah stunting, dan didapatkan $p$ value $=0,053(>0,05)$ yang bermakna tingkat pendidikan ibu tidak memiliki hubungan dengan perilaku ibu dalam pencegahan stunting. Selaras dengan penelitian ini, penelitian oleh Salamung et al. (2019) mendapatkan hasil p value = $0,230(>0,05)$ yang berarti tidak terdapat hubungan bermakna antara pendidikan ibu dengan perilaku pencegahan stunting di Wilayah Kerja Puskesmas Kabupaten Bondowoso. Penelitian lainnya juga mendapatkan hasil serupa dengan $\mathrm{p}$ value $=0,74(>0,05)$. Jika berdasarkan teori HPM (Health Promotion Model), terdapat faktor-faktor lain yang memberi pengaruh pada perilaku ibu dalam 
pencegahan stunting seperti faktor biologis dan psikologis, sehingga tingkat pendidikan yang termasuk faktor sosial budaya bukan merupakan faktor yang secara langsung mempengaruhi (Sholecha, Yunitasari, Armini, \& Arief, 2019). Begitu juga hasil penelitian Rufaida et al. (2020), dengan $\mathrm{p}$ value $=0,128$ menunjukkan bahwa tidak ditemukan hubungan antara pendidikan orang tua dengan terjadinya stunting pada balita. Sedangkan penelitian Fauzi et al. (2020), menemukan bahwa ada hubungan dari tingkat pendidikan ibu dengan kejadian stunting pada balita dengan $\mathrm{p}$ value $=0,013$.

Pada hasil analisa antara status pekerjaan ibu dengan perilakunya dalam mencegah stunting didapatkan $\mathrm{p}$ value $=0,003(<0,05)$ yang bermakna terdapat hubungan antara status pekerjaan ibu dengan perilaku pencegahan stunting. Penelitian lain memiliki hasil yang serupa dengan $\mathrm{p}$ value $=$ 0,000 yang berarti terdapat hubungan antara pekerjaan ibu dengan terjadinya stunting. Perilaku ibu dalam memberi nutrisi kepada balitanya sangat ditentukan oleh status pekerjaannya. Bekerja membuat ibu memiliki waktu cukup terbatas dengan anak balita sehingga perhatian ibu kepada perkembangan anak menjadi berkurang dan ibu tidak dapat mengontrol asupan makanan anak dengan baik (Savita \& Amelia, 2020). Fauzia et al. (2019), dalam penelitiannya menjelaskan bahwa status gizi balita sangat dipengaruhi oleh asupan nutrisinya. Ibu memerlukan waktu yang lebih bersama anak untuk memberi perhatian dan asupan nutrisi yang baik. Kondisi ibu yang memiliki pekerjaan berpengaruh dengan berkurangnya waktu ibu bersama anak, akibatnya akan mempengaruhi juga asupan gizi yang anak terima serta status gizinya.

Berdasarkan teori yang sudah ada serta hasil penelitian di lapangan, peneliti berasumsi bahwa pada penelitian ini status pekerjaan ibu memiliki hubungan dengan perilakunya dalam mencegah stunting karena ibu yang tidak memiliki perkerjaan lebih banyak memiliki waktu bersama anak, sehingga ibu dapat menerapkan pencegahan stunting dengan lebih baik seperti memberikan asi 6 bulan pertama, memberikan asupan makanan yang bergizi, mengikuti kegiatan posyandu secara rutin, serta menjaga kebersihan air dan sanitasi. Sedangkan ibu yang berkerja memiliki hambatan yang lebih banyak untuk menerapkan perilaku pencegahan stunting seperti tidak dapat membawa anak rutin ke posyandu dan memberikan ASI (Air Susu Ibu) eksklusif karena pekerjaan sehingga menggantinya dengan susu formula, serta kurang mengontrol asupan makanan anak karena biasanya anak dititipkan saat ibu sedang bekerja.

\section{Tabel 6. Analisa Hubungan Pengetahuan dan Sikap Ibu tentang Stunting dengan Perilaku Ibu dalam Pencegahan Stunting $(\mathrm{n}=74)$}

\begin{tabular}{lccc}
\hline \multicolumn{1}{c}{ Analisa } & \multicolumn{3}{c}{ Perilaku Ibu dalam Pencegahan Stunting } \\
\cline { 2 - 4 } & r spearman & P value & n \\
\hline $\begin{array}{l}\text { Pengetahuan Ibu tentang } \\
\text { Stunting }\end{array}$ & 0,193 & 0,100 & 74 \\
\hline $\begin{array}{l}\text { Sikap Ibu tentang } \\
\text { Stunting }\end{array}$ & 0,374 & 0,001 & 74 \\
\hline
\end{tabular}

Pada tabel 6 didapatkan hasil analisa uji Korelasi Spearman dengan p value $=0,100(>0,05)$, yang dapat diartikan bahwa H0 diterima yaitu tidak didapatkan hubungan yang berarti antara pengetahuan ibu dengan perilakunya dalam mencegah stunting pada balita di Posyandu Tunas Mekar 1 Kelurahan Krukut. Berdasarkan arah serta kekuatan hubungannya, hubungan kedua variabel termasuk hubungan yang positif namun lemah, yang berarti perilaku ibu dalam melakukan pencegahan stunting akan semakin baik jika pengetahuannya juga semakin tinggi. Penelitian ini serupa dengan penelitian lain di Kota Jambi yang mendapatkan $p$ value $=0,373(>0,05)$ (Arnita et al., 2020). Begitu juga penelitian lain oleh Harikatang et al. (2020), menunjukkan bahwa antara pengetahuan ibu dengan terjadinya balita stunting tidak memiliki hubungan yang bermakna ( $p$ value 
$=1,00)$. Sedangkan penelitian lain memperlihatkan hasil adanya hubungan antara pengetahuan ibu dengan perilakunya dalam pencegahan stunting dengan $p$ value $=0,007(<0,05)$ (Yunitasari, Pradanie, Arifin, Fajrianti, \& Lee, 2021).

Pengetahuan baik yang dimiliki seseorang tidak dapat memastikan sikap maupun perilakunya, karena pengetahuan juga tidak dapat memastikan seperti apa pola hidup yang dijalani seseorang tersebut. Kondisi ekonomi yang tidak mendukung walaupun pengetahuan ibu sudah baik akan mempengaruhi kemampuannya untuk menerapkan pola hidup yang sehat (Harikatang et al., 2020). Tidak adanya hubungan dari kedua variabel dalam penelitian ini dapat disebabkan karena terdapatnya faktor lain yang memberi pengaruh pada perilaku pencegahan stunting. Berdasarkan teori lawrence green, faktor pengetahuan termasuk faktor predisposisi yang dapat mempengaruhi perilaku kesehatan seseorang, namun terdapat faktor lain juga yaitu faktor pendukung seperti tersedianya fasilitas kesehatan serta faktor pendorong seperti dukungan keluarga, teman, serta petugas kesehatan (Asmuji \& Faridah, 2018). Jurnal lain menjelaskan bahwa faktor pendapatan, budaya dan pola asuh orang tua juga mempengaruhi perilaku pencegahan stunting. Hal ini disebabkan oleh orang tua dengan pendapatan yang cukup mampu untuk memenuhi kebutuhan makan anaknya, begitu juga pola asuh orang tua dalam memberi makan pada anak sangat mempengaruhi status gizi, pertumbuhan serta kesehatan anak sehingga anak dapat terhindar dari stunting. Sementara itu, nilai budaya yang bertentangan dengan anjuran kesehatan seperti pembatasan pola makan ibu hamil serta pemberian MPASI dini dapat membuat seorang ibu berperilaku kurang baik dan meningkatkan resiko anak mengalami stunting (Yunitasari et al., 2021).

Sedangkan hasil penelitian antara variabel sikap ibu dengan perilakunya dalam mencegah stunting yang didapatkan $\mathrm{p}$ value $=0,001(<0,05)$, sehingga dikatakan bahwa H1 diterima atau hubungan yang bermakna ditemukan antara sikap ibu dengan perilaku ibu dalam melakukan pencegahan stunting pada balita di Posyandu Tunas Mekar 1 Kelurahan Krukut. Dilihat dari arah dan kekuatan hubungannya, hubungan kedua variabel ini termasuk hubungan yang positif (searah) dan cukup kuat, yang berarti semakin positif sikap yang ibu miliki tentang stunting maka akan semakin baik pula perilakunya dalam mencegah stunting. Serupa dengan penelitian ini, penelitian Arnita et al. (2020), di Wilayah Kota Jambi mendapatkan bahwa ditemukan hubungan yang signifikan antara sikap ibu dengan upayanya dalam mencegah stunting pada anak balita ( $\mathrm{p}$ value = 0,030). Begitu juga penelitian lain di Madura yang mendapatkan serupa dengan $p$ value $=0,034$ $(<0,05)$. Sikap ibu yang kurang baik dalam praktik pemberian makan pada anak, dalam jangka panjang akan memberi dampak terhadap tumbuh kembang anak tersebut (Yunitasari et al., 2021).

Teori lawrence green yang menyatakan bahwa sikap seseorang termasuk dalam faktor predisposisi yang mempengaruhi perilaku kesehatannya sesuai dengan hasil penelitian yang didapatkan ini (Asmuji \& Faridah, 2018). Perilaku yang baik akan dapat tercermin jika sebuah pengetahuan yang dimiliki seseorang didukung oleh sikap yang positif (Arnita et al., 2020). Berdasarkan theory of planned behavior, sikap seseorang dipengaruhi oleh kepercayaan, seseorang akan memiliki sikap yang positif apabila ia percaya bahwa suatu perilaku akan menghasilkan keluaran yang baik (Nursalam, 2015). Berdasarkan teori serta hasil penelitian yang didapatkan, peneliti berpendapat bahwa dalam penelitian ini sikap ibu berhubungan dengan perilaku pencegahan stunting karena ibu balita dalam penelitian ini meyakini bahwa anak mereka perlu dicegah dari masalah gizi dan pencegahan stunting akan memberikan manfaat yang baik bagi balitanya, sehingga ibu memutuskan untuk menerapkan perilaku pencegahan stunting pada balitanya.

\section{SIMPULAN}

Berdasarkan hasil penelitian dapat disimpulkan bahwa rata-rata usia ibu balita adalah 32,41 tahun dengan mayoritas berpendidikan menengah dan berstatus tidak bekerja. Berdasarkan karakteristik balita, rata-rata balita dalam penelitian ini berusia 30,39 bulan, dengan mayoritas 
berjenis kelamin perempuan, dan berstatus gizi (TB/U) normal. Gambaran pengetahuan ibu mengenai stunting rata-rata memiliki pengetahuan yang cukup baik. Sedangkan rata-rata sikap dan perilaku ibu dalam mencegah stunting, ibu memiliki sikap perilaku yang sudah baik. Hasil analisa bivariat menunjukkan bahwa perilaku ibu dalam pencegahan stunting berhubungan dengan status pekerjaan ( $p$ value $=0,003$ ) dan sikap ibu ( $p$ value $=0,001)$, namun tidak berhubungan dengan usia ( $\mathrm{p}$ value $=0,305)$, tingkat pendidikan $(\mathrm{p}$ value $=0,053)$, dan pengetahuan ibu $(\mathrm{p}$ value $=0,100)$.

\section{SARAN}

Berdasarkan hasil penelitian serta uji statistik yang diperoleh, peneliti menyarankan pada keluarga termasuk orang tua balita agar dapat menjadikan penelitian ini sebagai motivasi dalam meningkatkan pengetahuan, sikap, serta perilaku dalam mencegah stunting pada balita. Bagi perawat ataupun tenaga kesehatan lain dianjurkan juga agar dapat menjadikan penelitian ini sebagai dasar dalam memberikan penyuluhan kesehatan dan memotivasi masyarakat untuk meningkatkan pengetahua mengenai stunting termasuk cara pencegahannya, agar masyarakat dapat melakukan pencegahan stunting dengan baik.

Selain itu, bagi institusi pendidikan dianjurkan agar dapat mempergunakan hasil penelitian ini sebagai referensi untuk kegiatan belajar mengajar mengenai pentingnya peningkatan pengetahuan, sikap serta perilaku ibu dalam mencegah stunting pada balita. Sedangkan bagi peneliti selanjutnya disarankan agar dapat menggunakan penelitian ini sebagai bahan referensi dalam melakukan penelitian yang serupa ataupun berbeda dengan metode yang lebih baik seperti wawancara (kualitatif), dan dengan cakupan tempat penelitian lebih luas serta sampel yang lebih banyak. Peneliti selanjutnya juga dapat meneliti faktor lain selain yang sudah digunakan dalam penelitian ini seperti faktor motivasi ibu, dukungan keluarga, dukungan lingkungan dan sebagainya.

\section{DAFTAR PUSTAKA}

Ariestia, M. (2020). Analisis Pengetahuan Dan Sikap Ibu Terhadap Pencegahan Stunting Pada Anak Di Masa Pandemi Covid -19 Di Kelurahan Korong Gadang. Jurnal Ilmiah Cerebral Medika, 2(2), 1-9. Retrieved from http://mpoc.org.my/malaysian-palm-oil-industry/

Arnita, S., Rahmadhani, D. Y., \& Sari, M. T. (2020). Hubungan Pengetahuan dan Sikap Ibu dengan Upaya Pencegahan Stunting pada Balita di Wilayah Kerja Puskesmas Simpang Kawat Kota Jambi. Jurnal Akademika Baiturrahim Jambi, 9(1), 7. https://doi.org/10.36565/jab.v9i1.149

Asmuji, \& Faridah. (2018). Promosi Kesehatan: Untuk Perawat di Rumah Sakit dan Puskesmas (1st ed.). Yogyakarta: Pustaka Panasea.

Dinas Kesehatan Kota Depok. (2020). Profil Kesehatan Kota Depok 2019. In Dinas Kesehatan Kota Depok. Retrieved from http://dinkes.depok.go.id/

Fauzi, M., Wahyudin, \& Aliyah. (2020). Hubungan Tingkat Pendidikan dan Pekerjaan Ibu balita dengan kejadian stunting di wilayah kerja puskesmas $\mathrm{x}$ kabupaten indramayu. Prosiding Seminar Nasional Kesehatan, 9-15. Retrieved from http://ejurnal.stikesrespatitsm.ac.id/index.php/semnas/article/view/257

Fauzia, N. R., Sukmandari, N. M. A., \& Triana, K. Y. (2019). Hubungan Status Pekerjaan Ibu Dengan Status Gizi Balita. Journal Center of Research Publication in Midwifery and Nursing, 3(1), 28-32. https://doi.org/10.36474/caring.v3i1.101

Harikatang, M. R., Mardiyono, M. M., Karisma, M., Babo, B., Kartika, L., \& Tahapary, P. A. (2020). Hubungan pengetahuan dan sikap ibu dengan kejadian balita stunting di satu kelurahan di tangerang. Jurnal Mutiara Ners, 3(2), 76-88. Retrieved from http://114.7.97.221/index.php/NERS/article/view/1178

Hasmi. (2016). Metode Penelitian Kesehatan. Jayapura: In Media.

Kemenkes RI. (2018). Warta Kesmas - Cegah Stunting Itu Penting. Warta Kesmas, 02, 1-27. 
Nursalam. (2015). Metodologi Penelitian Ilmu Keperawatan. In Metodologi Penelitian Ilmu Keperawatan (4th ed.). Jakarta: Salemba Medika.

Peraturan Presiden RI. (2020). Rencana Pembangunan Jangka Menengah Nasional Tahun 2020-2024 Lampiran II: Proyek Prioritas Strategis (Major Project).

Pusdatin Kemenkes RI. (2018). Buletin Stunting. Kementerian Kesehatan RI, 301(5), 1163-1178.

Riskesdas. (2018). Laporan Nasional Riskesdas 2018. Badan Penelitian Dan Pengembangan Kesehatan, p. 198. Jakarta: Lembaga Penerbit Badan Penelitian dan Pengembangan Kesehatan.

Rufaida, F. D., Raharjo, A. M., \& Handoko, A. (2020). The Correlation of Family and Household Factors on The Incidence of Stuntingon Toddlers in Three Villages Sumberbaru Health Center Work Area of Jember. Journal of Agromedicine, 6(1), 1-6.

Salamung, N., Haryanto, J., \& Sustini, F. (2019). Faktor-Faktor yang Berhubungan dengan Perilaku Pencegahan Stunting pada Saat Ibu Hamil di Wilayah Kerja Puskesmas Kabupaten Bondowoso. Jurnal Penelitian Kesehatan Suara Forikes, 10(4), 264-269.

Savita, R., \& Amelia, F. (2020). Hubungan Pekerjaan Ibu , Jenis Kelamin , dan Pemberian Asi Eklusif Terhadap Kejadian Stunting Pada Balita 6-59 Bulan di Bangka Selatan The Relationship of Maternal Employment, Gender, and ASI Eklusif with Incident of Stunting inToddler Aged 659 Months. Jurnal Kesehatan Poltekkes Kemenkes Ri Pangkalpinang, 8(1), 6-13.

Sholecha, R. P., Yunitasari, E., Armini, N. K. A., \& Arief, Y. S. (2019). Analisis Faktor yang berhubungan dengan Pencegahan Stunting pada Anak Usia 2-5 Tahun berdasarkan Teori Health Promotion Model (HPM). Pediomaternal Nursing Journal, 5(1), 49. https:/ / doi.org/10.20473/pmnj.v5i1.12362

SSGBI, T. (2019). Studi Status Gizi Balita Di Indonesia Tahun 2019.

TNP2K. (2017). 100 Kabupaten/Kota Prioritas Untuk Intervensi Anak Kerdil (Stunting).

TNP2K. (2019). Strategi Nasional Percepatan Pencegahan Anak Kerdil (Stunting). Jakarta.

UNICEF, WHO, \& World Bank. (2020). Levels and trends in child malnutrition: Key findings of the 2020 Edition of the Joint Child Malnutrition Estimates. Geneva: WHO, 24(2), 1-16. Retrieved from https://www.who.int/publications/i/item/jme-2020-edition

Wulandari, H., \& Kusumastuti, I. (2020). Peran Bidan, Peran kader, Dukungan Keluarga dan Motivasi Ibu terhadap Perilaku Ibu dalam Pencegahan Stunting. Jurnal Ilmiah Kesehatan, 19(2), 73-80. https://doi.org/10.33221/jikes.v19i02.548

Yunitasari, E., Pradanie, R., Arifin, H., Fajrianti, D., \& Lee, B. (2021). Determinants of Stunting Prevention among Mothers with Children Aged 6 - 24 Months. Macedonian Journal of Medical Sciences, 9, 378-384. https://doi.org/https://doi.org/10.3889/oamjms.2021.6106 